\title{
Modification of Asphalt Binder with Waste Expanded Polystyrene (EPS) Foam
}

\author{
Kürşat Yıldı1 (iD), Harun Kınacı (iD), Mert Atakan* ${ }^{3 *}$ \\ ${ }^{1}$ Gazi University, Faculty of Technology, Department of Civil Engineering, Ankara, Turkey \\ ${ }^{2}$ Faculty of Economics and Administrative Sciences, Erciyes University, Kayseri, Turkey \\ ${ }^{3}$ Gazi University, Faculty of Technology, Department of Civil Engineering, Ankara, Turkey \\ *mertatakan@gazi.edu.tr \\ *Orcid: 0000-0003-1878-2111
}

Received: 28 February 2021

Accepted: 26 July 2021

DOI: $10.18466 /$ cbayarfbe. 885696

\begin{abstract}
Waste polymers are widely used in asphalt modification, especially, in order to reduce their detrimental effect on the environment. This study discusses the usability of waste expanded polystyrene (EPS) foam in asphalt modification. In this respect, the EPS foam, which produces waste in both production and use stages, was mixed with bitumen by weight at the ratios of $2 \%, 4 \%, 6 \%$, and $8 \%$, and dry modification method was employed. The penetration, ductility, softening point, flash point, and specific gravity values of virgin bitumen were compared with waste EPS foam modified bitumen. The comparison was made by both graphical and statistical methods. A strong correlation between the physical properties of modified asphalt and the ratio of EPS foam was observed. A drop was observed in penetration and ductility values. Besides, it was found by statistical analyses that $2 \%$ of the increase in the additive ratio is not sufficient to make a significant difference in the physical properties of bitumen, therefore, the increase should be at least $4 \%$. Overall, it is concluded that EPS foam additive can be used in bitumen modification for hot regions where low penetration is required.
\end{abstract}

Keywords: Asphalt Binder, Bitumen Modification, EPS, Polystyrene Foam, Statistical Evaluation.

\section{Introduction}

Hot bituminous mixtures (HBMs) are the most common type of material using in pavement constructions. HBMs are preferred due to their service life performance, stability, durability, water-resistance, and comfort criteria. Recently increased traffic volume and axle loads have created a great necessity to improve these criteria [1].

It is a well-known fact that the rheological behavior of bitumen is significantly heat-related and low thermal susceptibility is vital for the bitumen. Bitumen at low temperatures is brittle due to its high stiffness which makes it vulnerable to thermal and fatigue cracking. On the other hand, bitumen at high temperatures tends to flow which gives rise to permanent deformations under traffic loads such as rutting [2]. Accordingly, polymers modification in bitumen enhances its performance at high, low, and intermediate temperatures. They can reduce thermal and fatigue cracking at low temperatures in the asphalt mixture. Also, they can increase the resistance to permanent deformation at high temperatures [2-4].

Today, with the development of the petroleum industry, synthetic polymers such as polypropylene (PP), polyethylene (PE), and polystyrene (PS) have become indispensable parts of our lives. This brought about the environmental waste problem. PS foam represents $70 \%$ of the total plastic waste in the oceans due to its low recycling rate. Approximately 3 million tons of PS waste are threatening the environment due to their chemical stability [5-8]. Although this threat is tried to be eliminated through landfills and incineration, landfill brings an extra cost, and incineration results in toxic gas emissions, which is detrimental to the environment [5]. Polymeric materials are also considered a good bitumen modifier because of their chemical structure composed of mostly carbon elements [7]. Thus, many studies have been done on asphalt modification with polymeric materials such as PP [9], PE [10], and PS [8,11-14]. For 
instance, Vila-Cortavitarte et al. (2018) has performed a life cycle assessment on waste PS modified bitumen and they suggest that using modified bitumen might reduce its environmental impact significantly because it provides longer performance life [14]. In another study, bitumen has been modified with PS and transpolyoctenamer in the presence of a cross-linking agent [12]. They have reported that modified bitumen has provided good storage stability, improved in elastic recovery, and showed better overall performance compared to virgin asphalt.

The expanded polystyrene (commonly referred to as EPS) has great impact strength, acoustic and heat isolation properties. Also, its lightness is another advantage. Therefore, EPS is generally used in the package and packaging sector as well as in the building industry as heat or acoustic isolation material $[15,16]$. EPS comprises small PS beads that are obtained from styrene by the polymerization process. Once polymerization is completed, EPS is infused with a blowing agent (e.g., pentane and hexane). After that, small volumes of gas are entrapped between polystyrene beads, and expansion is achieved [17]. EPS contains more than $95 \%$ of air which makes it difficult to accumulate as waste. Besides, its recycling process is complicated and costly due to its high volume [3]. Thus, using EPS in asphalt modification can contribute to handling this environmental pollutant. Also, EPS starts to soften at a temperature above $100{ }^{\circ} \mathrm{C}$ [18]. That is why it can stay durable at service temperatures of asphalt pavements.

Nciri et al. (2020) have studied the chemical background of asphalt modification with waste EPS, and they have suggested that waste EPS can be used as a bitumen modifier [16]. However, the limitation of their study is not to address the physical properties of the asphalt. On the other hand, some studies have been done relating to the effect of EPS modification on the physical and rheological properties of asphalt binder $[3,19,20]$. They have suggested that waste EPS modification enhances asphalt's physical performance. For instance, Mahida et al. (2021) have studied waste EPS modified asphalt with mechanical analysis (e.g., penetration, softening point, viscosity), rheological tests, electron microscopy, infrared stereoscopy, and Marshall stability [3]. They have demonstrated incorporation of waste PS in bitumen modification at different percentages significantly improves the properties as compared to virgin bitumen. They have got satisfactory results in rutting and fatigue parameters in dynamic shear rheometer (DSR). Besides, they have reported an increase in stiffness of the bitumen with waste PS according to penetration and softening point results. The raise in the stiffness is also supported by other studies [19-21]. Although several studies have been carried out on EPS modification of asphalt binder, no single study exists that uses statistical evaluation methods.

This study investigates the effect of waste EPS foam on the physical properties of the asphalt binder. In line with this purpose, 50/70 penetration grade of asphalt cement was modified with waste EPS at the ratio of $2 \% ; 4 \%$; $6 \%$, and $8 \%$. The penetration, ductility, softening point, flash point, and specific gravity tests were performed according to related standards. The reason to choose these tests was to evaluate stiffness, temperature susceptibility, and safety of the modified bitumen. Obtained results are interpreted and evaluated with statistical methods differently from other studies.

\section{Materials and Methods}

In this study, 50/70 penetration grade bitumen, which was supplied from İzmit Tüpraş refinery, was used, and the properties of the bitumen are given in Table 1 .

EPS was used in the study. Generally, their density varies from $0.028-0.045 \mathrm{~g} / \mathrm{cm}^{3}$. In this study EPS, whose density is $0.032 \mathrm{~g} / \mathrm{cm}^{3}$, was used. Typical properties of the PS are given in Table 2. The dry method, which is one of the modified bitumen preparation methods, was used in the study. In this method, virgin bitumen and waste EPS foam were mixed in a steel bowl before melting the EPS (Figure 1).

Table 1. Properties of the bitumen [22].

\begin{tabular}{llc}
\hline Parameters & $\begin{array}{l}\text { Value } \\
\text { from the } \\
\text { Supplier }\end{array}$ & $\begin{array}{c}\text { Laboratory } \\
\text { Tests } \\
\text { Results }\end{array}$ \\
\hline Penetration $(0.1 \mathrm{~mm})$ & $50 / 70$ & 66.3 \\
Softening Point $\left({ }^{\circ} \mathrm{C}\right)$ & $46-54$ & 50.4 \\
Flash Point $\left({ }^{\circ} \mathrm{C}\right)$ & $230(\mathrm{Min})$ & 314 \\
Solubility $(\%)$ & $99(\mathrm{Min})$ & - \\
Softening point rise $\left({ }^{\circ} \mathrm{C}\right)$ & $9(\mathrm{Max})$ & - \\
Resistance to hardening $(\mathrm{a})$ at $163^{\circ} \mathrm{C}$ & & - \\
- Loss on heating $(\%)$ & $0.5(\mathrm{Max})$ & \\
- Penetration after heating $(\%)$ & $50(\mathrm{Min})$ & \\
- Softening point after heating $\left({ }^{\circ} \mathrm{C}\right)$ & $48(\mathrm{Min})$ & \\
\hline
\end{tabular}

Table 2. Typical properties of PS [3].

\begin{tabular}{ll}
\hline Property & Value \\
\hline IUPAC name & Poly $(1-$ phenylethene $)$ \\
Common name & Thermocol \\
CAS number & $9003-53-6$ \\
Abbreviations & PS \\
Chemical formula & $\left(\mathrm{C}_{8} \mathrm{H}_{8}\right)_{\mathrm{n}}$ \\
Density & $0.96-1.04 \mathrm{~g} / \mathrm{cm}^{3}$ \\
Melting point & $\sim 240{ }^{\circ} \mathrm{C}$ \\
\hline
\end{tabular}

The waste EPS was added into the bowl, which contains $150^{\circ} \mathrm{C}$ hot bitumen, at certain percentages of bitumen weight $(2 \%, 4 \%, 6 \%$, and $8 \%$ ). These ratios were selected based on previous studies where additive ratios are below 10\% [16,19-21]. Then, EPS and the bitumen 
mixed homogeneously. Next, the mixture was added to the oven whose temperature was adjusted to $150^{\circ} \mathrm{C}$. The mixture was kept in the oven for 2 hours in order to provide EPS to melt, and thus obtain a homogeneous mixture. Once EPS was softened and mixed with bitumen, entrapped air in the EPS was disappeared. In other words, EPS became normal PS. After that, the homogeneous mixture was taken into test equipment within the standards following; penetration (ASTM D5D5M-13), ductility (AASHTO T 51-09), softening point (AASHTO T 53), flash point (ASTM D 92-18), and specific gravity. Some stages of the experimental process are demonstrated in Figure 2.

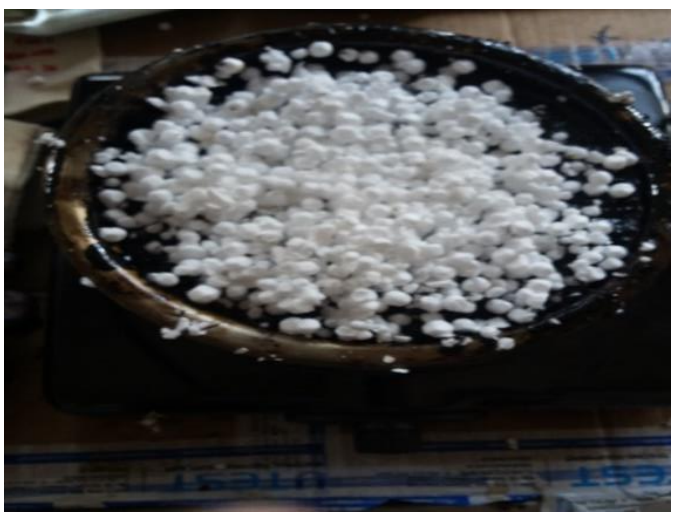

Figure 1. The process of mixing EPS foam into the bitumen.
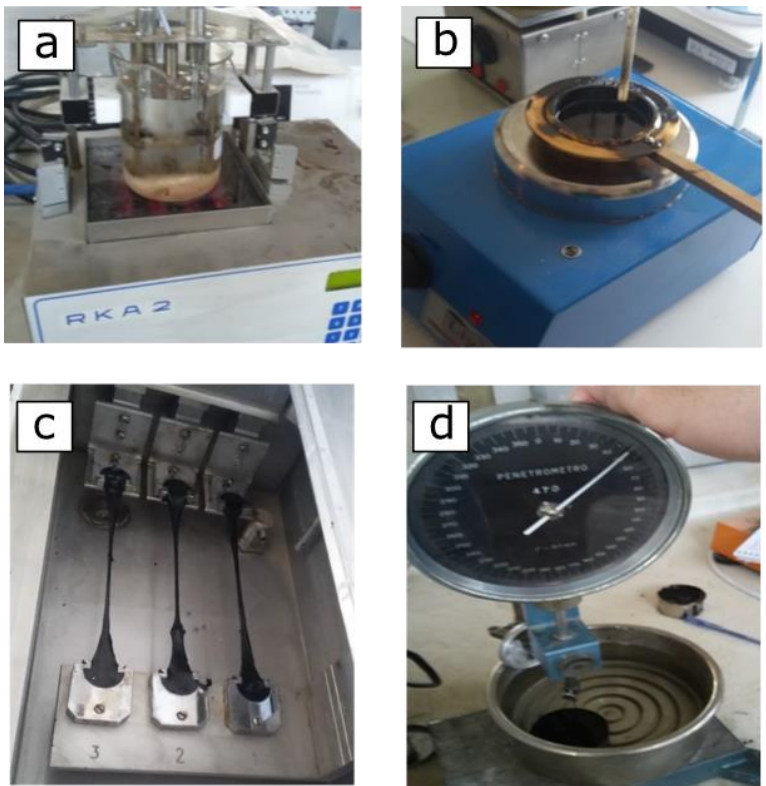

Figure 2. Experimental process a) Softening Point b) Flash Point c) Ductility d) Penetration.

\section{Results and Discussion}

The changes in physical properties of EPS modified bitumen were evaluated and interpreted compared to the $50 / 70$ penetration virgin bitumen. The findings are given in Table 3 . The data presented here are the means of the values obtained as a result of three experiments for penetration, ductility, and softening point, respectively. Standard deviations of the results are illustrated in Figure 3 as error bars. Table data were interpreted by graphing for each physical property and using statistical methods.

Table 3. Modified Bitumen Physical Properties (Modified Bitumen Physical Properties).

\begin{tabular}{|l|l|l|l|l|l|l|}
\hline \multirow{2}{*}{$\begin{array}{l}\text { Physical } \\
\text { Properties }\end{array}$} & \multicolumn{6}{|l}{ Polystyrene rate (\%) } \\
\cline { 2 - 8 } & Standard & $\mathbf{0 \%}$ & $\mathbf{2 \%}$ & $\mathbf{4 \%}$ & $\mathbf{6 \%}$ & $\mathbf{8 \%}$ \\
\hline $\begin{array}{l}\text { Penetration } \\
(\mathrm{x} 0.1 \mathrm{~mm})\end{array}$ & $\begin{array}{l}\text { ASTM D5- } \\
\text { D5M-13 }\end{array}$ & 66.3 & 62.7 & 61.3 & 57.7 & 49.7 \\
\hline $\begin{array}{l}\text { Ductility } \\
(\mathrm{cm})\end{array}$ & $\begin{array}{l}\text { ASHTO T } \\
51-09\end{array}$ & 122 & 114 & 109 & 102 & 83 \\
\hline $\begin{array}{l}\text { Softening } \\
\text { point }\left({ }^{\circ} \mathrm{C}\right)\end{array}$ & $\begin{array}{l}\text { ASHTO T } \\
53\end{array}$ & 50.4 & 49.8 & 49.5 & 49.3 & 49.1 \\
\hline $\begin{array}{l}\text { Flash Point } \\
\left({ }^{\circ} \mathrm{C}\right)\end{array}$ & $\begin{array}{l}\text { ASTM D } \\
92-18\end{array}$ & 314 & 320 & 342 & 354 & 360 \\
\hline $\begin{array}{l}\text { Specific } \\
\text { gravity } \\
\left(\mathrm{g} / \mathrm{cm}^{3}\right)\end{array}$ & $\begin{array}{l}\text { ASTM-D } \\
70-03\end{array}$ & 1.030 & 1.036 & 1.050 & 1.058 & 1.065 \\
\hline $\begin{array}{l}\text { Penetration } \\
\text { Index (PI) }\end{array}$ & $\begin{array}{l}\text { Pfeiffer and } \\
\text { Van } \\
\text { Doormaal } \\
(1936)[23]\end{array}$ & -0.41 & -0.71 & -0.84 & -1.04 & -1.44 \\
\hline
\end{tabular}

\subsection{Penetration}

When the penetration data are examined in Table 3 , the modified bitumen penetration values decreased as the EPS percentage increased. The amount of this change is given in Figure 3a graphicly. When each polystyrene additive percentage increased by $2 \%$, it was observed that pure bitumen penetration decreased by $5.53 \%$, $7.53 \%, 13.53 \%$, and $25.13 \%$, respectively.

In order to determine the statistical significance of this decrease, the correlation value between the polystyrene percentage and the penetration value was calculated, and a strong negative value of -0.958 was obtained. The p-value of the correlation value is 0.01 (Table 4). It is concluded that the correlation coefficient is significant for the case where the meaning level is 0.05 [24]. From these results, it is interpreted that as the percentage of polystyrene additive increases, the penetration value decreases.

It is clear that this decrease in the penetration values of bitumen will lead to an increase in viscosity. According to reference [25], this increase makes workability difficult, in other words, compaction of the asphalt mixture becomes more difficult. But the decrease in penetration provides higher resistance against deformations such as rutting as stated in reference [26]. Besides, it is thought that the penetration value can be adjusted by using polystyrene additive in hot climates where low penetration is required. When it comes to the rheology, rheological properties of the modified bitumen were not completely evaluated in this study. 
However, this issue is addressed by Mahida (2021) [3]. They have stated that PS modified bitumen showed better rutting performance and its elastic properties largely increased.

Table 4. Correlation Analysis Results

\begin{tabular}{|c|c|c|c|}
\hline $\begin{array}{l}\text { First } \\
\text { Variable }\end{array}$ & $\begin{array}{l}\text { Second } \\
\text { Variable }\end{array}$ & $\begin{array}{l}\text { Correlation } \\
\text { Coefficient }\end{array}$ & p-Value \\
\hline $\begin{array}{l}\text { Penetration (x } \\
0.1 \mathrm{~mm})\end{array}$ & \multirow{5}{*}{$\begin{array}{l}\text { EPS } \\
(\%)\end{array}$} & -0.958 & $0.010^{*}$ \\
\hline Ductility $(\mathrm{cm})$ & & -0.963 & $0.009 *$ \\
\hline $\begin{array}{l}\text { Softening } \\
\text { point }\left({ }^{\circ} \mathrm{C}\right)\end{array}$ & & -0.967 & $0.007^{*}$ \\
\hline $\begin{array}{ll}\begin{array}{l}\text { Flash } \\
\left({ }^{\circ} \mathrm{C}\right)\end{array} & \text { Point } \\
\end{array}$ & & 0.979 & $0.004^{*}$ \\
\hline $\begin{array}{l}\text { Specific } \\
\text { gravity } \\
\left(\mathrm{g} / \mathrm{cm}^{3}\right)\end{array}$ & & 0.992 & $0.001^{*}$ \\
\hline
\end{tabular}

\subsection{Ductility}

When ductility values are examined in Table 3 , the ductility values of modified bitumen decreased as the additive ratio increased. The amount of this change is shown in Figure 3c graphicly. In each $2 \%$ increase of polystyrene additive, it was observed a decrease of $6.56 \%, 10.66 \%, 16.40 \%$, and $31.97 \%$ in ductility of pure bitumen, respectively.
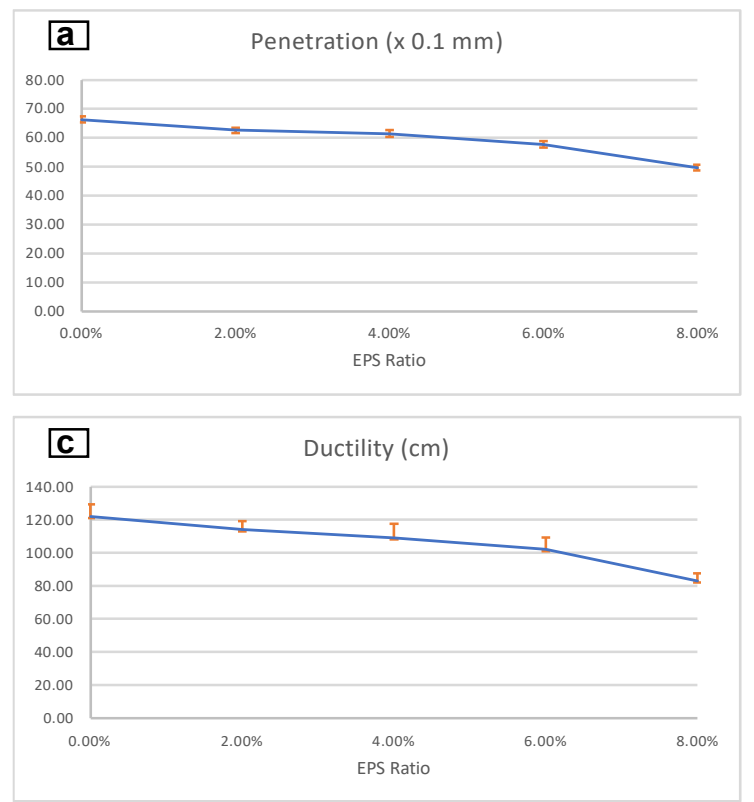

In order to determine the statistical significance of this decrease, the correlation value between polystyrene percentage and ductility value was calculated, and a strong negative correlation value of -0.963 was obtained. The $\mathrm{p}$-value of the correlation value found is 0.009 (Table 4). It is concluded that the correlation coefficient is significant for the case where the meaning level is 0.05 . From these results, it is interpreted that the ductility value decreases with polystyrene additives.

The ductility test is commonly accepted as a controversial test because of its empirical nature, low reproducibility, and the unclear relationship between the measured results and basic material characteristics [27]. However, field data support that there is a good correlation between asphalt ductility and pavement cracking. Cracks are more likely to occur as ductility decrease $[28,29]$. Therefore, the decrease in ductility may not be interpreted as good especially in cold regions. Nonetheless, ductility values of the modified bitumen are met with the specification limits except for the value for $8 \%$ additive. That is why it might be used for hot regions up to $6 \%$ for a similar reason with penetration values.
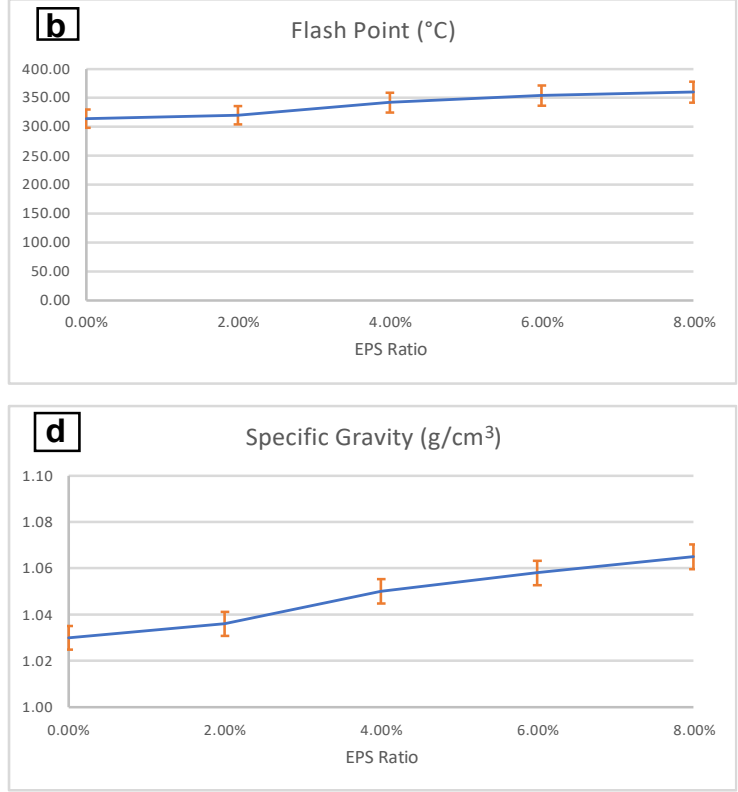

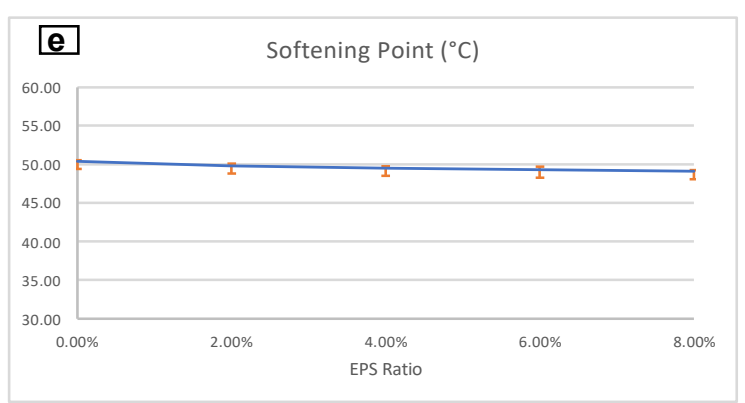

Figure 3. Change of the physical properties a) Penetration b) Flash Point c) Ductility d) Penetration e) Softening Point 


\subsection{Softening Point}

When the softening point values are examined in Table 3 , the softening point values of modified bitumen decreased as the EPS ratio increased. The amount of this change is shown in Figure 3e graphicly. Each 2\% increase of polystyrene additive caused a decrease of $1.19 \%, 1.88 \%, 2.18 \%$, and $2.57 \%$, respectively, in the softening point of the pure bitumen.

In order to determine the statistical significance of this decrease, the correlation value between polystyrene percentage and softening point value was calculated, and a strong negative value of -0.967 was obtained. The $\mathrm{p}$-value of the correlation value found is 0.007 (Table 4). It is concluded that the correlation coefficient is significant for the case where the meaning level is 0.05 . From these results, it is interpreted that the softening point value decreases as the percentage of polystyrene additive increases.

The softening point test measures the temperature value where bitumen reaches a certain softness. Bitumen has an approximately penetration value of 800 or absolute viscosity of 13000 poises when it is at its softening point [30]. Therefore, softening point test reveals the relationship between viscosity and temperature of the bitumen. In other words, the viscosity of the bitumen depends on the difference between its temperature and softening point. The slight decrease in the softening point of modified bitumen may affect badly its performance especially in hot regions due to low viscosity. However, this decrease is slight and remains in the limitation of base bitumen. Therefore, the modified bitumen can be used, because it can contribute to reclaim waste EPS and reduce bitumen consumption.

Furthermore, the softening point can be used along with penetration to calculate the temperature susceptibility of the bitumen. For this purpose, Penetration Index (PI) was defined by Pfeiffer and Van Doormaal (1936) [23]. By assuming bitumen has a penetration of 800 at softening point, PI values were calculated for each PS ratio (Table 3). These calculation steps are well explained in reference [30]. There was a constant decrease in PI values which means a rise in temperature susceptibility. However, this decrease remained within the limits of normal bitumen. Because bitumen with PI values between -2 and 2 can be referred to as normal bitumen $[30,31]$.

\subsection{Flash Point}

The change of flash point values with the EPS ratio is given in Table 3. It illustrates that flash point values of modified bitumen increased, as the additive ratio increased. The amount of change, according to the EPS ratio, is graphicly demonstrated in Figure 3b. Each $2 \%$ increase in the EPS ratio gives rise to an ascend in flash point by $1.91 \%, 8.91 \%, 12.73 \%$, and $14.64 \%$, respectively.

In order to determine the statistical significance of this increase, the correlation value between the polystyrene percentage and flash point value was calculated, and a strong positive correlation value of 0.979 was obtained. The $\mathrm{p}$-value of the correlation value found is 0.004 (Table 4). It is concluded that the correlation coefficient is significant for the case where the meaning level is 0.05 .

From these results, it is interpreted that the flash point value increases as the percentage of polystyrene additive increases. When the results are evaluated in the light of literature, the determination of the flash point of petroleum products or flammable materials is a crucial parameter that should be determined in terms of safety and environmental damage [32]. In this respect, polystyrene-modified bitumen shows good behavior. This situation also increases the safety range by meeting the requirements for the transportation of bitumen and HBM.

\subsection{Specific Gravity}

When the specific gravity values of bitumen are examined in Table 3 , the specific gravity of modified bitumen increases as the additive ratio increases. The amount of change of the specific gravity according to the additive ratio is given in Figure 3d. Each 2\% increase in the EPS ratio is caused to a rise in the bitumen specific gravity value by $0.58 \%, 1.94 \%, 2.71 \%$, and $3.39 \%$, respectively.

In order to determine the statistical significance of this increase, the correlation value between polystyrene percentage and specific gravity value was calculated, and a strong positive correlation value of 0.992 was obtained. The p-value of the correlation value is 0.001 (Table 4). It is concluded that the correlation coefficient is significant for the case where the meaning level is 0.05 . From these results, it is interpreted that the specific gravity value increases as the percentage of polystyrene additive increases.

The specific gravity value of the asphalt binder is essential to determine the volumetric specifications of the asphalt mix. Because while preparing asphalt-mix, mixing ratios are often expressed as percent by weight. In another aspect, the specific gravity value is particularly important for the determination of the critical characteristic of the asphalt mixture, such as bitumen film thickness [33]. In this respect, it is concluded that polystyrene-modified bitumen is within the specification limits and denser than pure bitumen. This can contribute to bitumen stability positively, as well as to increase durability. 


\subsection{Inferential Statistics}

Another point that needs to be addressed with this experimental study is the significance of the differences between the values in different amounts of polystyrene for each variable (penetration ductility, etc.). With these tests, it is possible to obtain information about how much the amount of penetration should be increased to make a significant difference according to the relevant parameter.

For this purpose, the significance of changes in the penetration, ductility, and softening point values obtained by three different experiments according to different polystyrene ratios were evaluated by KruskalWallis Test and the p-values obtained as 0.011, 0.031, and 0.022 , respectively. Penetration, ductility, and softening point values are interpreted separately for different polystyrene values where all of these values are less than 0.05 meaning level. Post hoc tests were also performed for different polystyrene values to determine the ratios between these differences.

Table 5. Results of Kruskal-Wallis Test

\begin{tabular}{|l|l|l|l|}
\hline $\begin{array}{l}\text { Group } \\
\text { Variables }\end{array}$ & $\begin{array}{l}\text { Dependent } \\
\text { Variables }\end{array}$ & $\begin{array}{l}\text { Kruskal-Wallis } \\
\text { Test } \\
\text { p-values }\end{array}$ & $\begin{array}{l}\text { Leven's } \\
\text { Test } \\
\text { p-values }\end{array}$ \\
\hline \multirow{2}{*}{$\begin{array}{l}\text { EPS Ratio } \\
\text { (5 Groups) }\end{array}$} & Penetration & $0.011^{*}$ & $0.743^{* *}$ \\
\cline { 2 - 4 } & Ductility & $0.031^{*}$ & $0.810^{* *}$ \\
\cline { 2 - 4 } & Softening Point & $0.022^{*}$ & $0.547^{* *}$ \\
\hline $\begin{array}{l}* \text { Meaningful at } 0.05 \text { significance level } \\
\text { * Not meaningful at 0.05 significance level (Homogeneous } \\
\text { variances) }\end{array}$
\end{tabular}

There are several Post Hoc tests in the literature. These are divided into two main groups according to whether the variances of the variables to be compared are equal or not. For this purpose, homogeneity of variances was tested by Levene's test, and p-values were obtained as $0.743,0.810$, and 0.547 according to the variables of penetration, ductility, and softening point, respectively (Table 5). When the meaning level is above 0.05 , it is interpreted that they have the same variance according to different polystyrene values for each variable. In this case, the Post Hoc test should be selected from the tests that run under the assumption that the variances are equal. For this reason, the Scheffe test, which provides this feature, was applied for binary comparisons (Table $6)$.

In the paired comparisons for the penetration variable, the penetration value was statistically insignificant only when the polystyrene ratio was between $2 \%$ and $4 \%$ (pvalue $=0.726$ ). In other words, the use of polystyrene at the ratio of $2 \%$ or $4 \%$ does not cause a statistically significant difference in the penetration value. In all other possible binary comparisons, penetration values for different polystyrene ratios were found to be different (Table 6).
Table 6. Scheffe Post Hoc test results of penetration, ductility, and softening point

\begin{tabular}{|c|c|c|c|c|}
\hline \multicolumn{2}{|c|}{$\begin{array}{l}\text { EPS } \\
\text { Ratio } \\
(\%)\end{array}$} & $\begin{array}{l}\text { p-Value } \\
\text { for Penetration }\end{array}$ & $\begin{array}{l}\text { p-Value } \\
\text { for Ductility }\end{array}$ & $\begin{array}{l}\text { p-Value } \\
\text { for } \\
\text { Softening }\end{array}$ \\
\hline \multirow{4}{*}{0} & 2 & $0.036^{*}$ & 0.716 & $0.048^{*}$ \\
\hline & 4 & $0.005^{*}$ & 0.302 & $0.002 *$ \\
\hline & 6 & $0.000 *$ & 0.056 & $0.001^{*}$ \\
\hline & 8 & $0.000 *$ & $0.001^{*}$ & $0.000^{*}$ \\
\hline \multirow{3}{*}{2} & 4 & 0.726 & 0.928 & 0.290 \\
\hline & 6 & $0.005^{*}$ & 0.371 & 0.114 \\
\hline & 8 & $0.000 *$ & $0.004 *$ & $0.020^{*}$ \\
\hline \multirow{2}{*}{4} & 6 & $0.036^{*}$ & 0.800 & 0.996 \\
\hline & 8 & $0.000^{*}$ & $0.012^{*}$ & 0.458 \\
\hline 6 & 8 & $0.000 *$ & 0.073 & 0.809 \\
\hline
\end{tabular}

The ratio of polystyrene in binary comparisons for the ductility variable is shown in Table 6. The corresponding $\mathrm{p}$-values are given in the table. According to the results obtained, the difference in ductility values was statistically insignificant when the additive ratio is $2 \%$ or $4 \%$. It was concluded that the additive ratio should be at least $6 \%$ in order to affect the ductility of the virgin asphalt. Furthermore, according to the results, the polystyrene ratio should change at least $4 \%$ (e.g., from $4 \%$ to $8 \%$ ) in order to have a significant change in ductility value.

Binary comparisons of the EPS ratio for the softening point are listed in Table 6 . The corresponding p-values are given in the table. The table demonstrates that the softening point values where the polystyrene ratio is $0 \%$ are different from other polystyrene ratios. Therefore, the addition of EPS causes a meaningful change in the softening point. However, if the polystyrene rate is $2 \%$ or more, the polystyrene rate must be changed at least $4 \%$ to create a meaningful change in the softening point.

\section{Conclusions}

Waste utilization is an issue that should be considered in almost all activities of developed and developing countries. That is why, both in the world and in Turkey, many non-governmental and governmental organizations continue their activities by looking for new utilization fields of wastes. In this respect, using waste EPS in asphalt modification was studied, and this paper not only aims to solve an engineering problem but also employs an environmentalist approach. The following conclusions can be drawn from this study:

- $\quad$ EPS modification of AC 50/70 penetration grade bitumen with the additive ratio of $2 \%, 4 \%$, and $6 \%$ remain within the limit values of ASTM D5-D5M13 standard, but $8 \%$ additive ratio exceeded the limits of the standard.

- Ductility of the pure bitumen decreased with EPS additive, which is considered a negative result 
usually. But it may give rise to a decrease in thermal sensitivity, which is a good point in hot climates.

- The EPS additive does not significantly affect the softening point.

- Flash point of the pure bitumen raised with EPS additive, which may improve storing, transport, and environmental sensitivity in terms of safety.

- It has been observed that the addition of EPS increases the specific gravity of the bitumen, which may affect the service life positively.

- There is a strong correlation between the physical properties of asphalt cement and EPS ratios. It is a known fact that physical properties are affected by each other. This reality is especially strong between ductility and softening point.

- It is found that a $2 \%$ increase in the EPS ratio had no significant effect on the physical properties of the asphalt. Thus, considering inferential statistical analysis, an optimum increase ratio should be determined as $4 \%$ instead of $2 \%$ in further optimizing research.

- If the bitumen is modified with a $4 \%$ EPS ratio, $1.25 \mathrm{~m}^{3}$ waste EPS can be reclaimed for every ton of bitumen usage. In other words, an average truckload waste EPS can be recycled with 16 tons of bitumen.

The study makes a baseline level discussion of using EPS to modification of asphalt. Further research may be done in order to improve its results, such as the aging or fatigue behavior of EPS modified asphalt. One of the limitations of this study is the number of specimens. That is why further research can be done with more specimens in order to drop the error in statistical analyses. In this way, the results could approximate practical applications. Besides, more broadly, research is needed to determine morphological characteristics of modified bitumen.

\section{Author's Contributions}

Kürşat Yıldız: Study conception and design, data collection, analysis and interpretation of results, draft manuscript preparation

Harun Kınacı: Analysis and interpretation of results, draft manuscript preparation,

Mert Atakan: Analysis and interpretation of results, draft manuscript preparation,

\section{Ethics}

There are no ethical issues after the publication of this manuscript.

\section{References}

1. Papagiannakis, A.T. and Masad, E.A. Pavement Design and Materials; John Wiley \& Sons, Inc.: Hoboken, New Jersey, 2008.

2. García-Morales, M., Partal, P., Navarro, F.J., Martínez-Boza, F., Gallegos, C., González, N., González, O., and Muñoz, M.E. 2004. Viscous properties and microstructure of recycled eva modified bitumen. Fuel. 83 (1): 31-38.

3. Mahida, S., Shah, Y.U., and Sharma, S. 2021. Analysis of the Influence of Using Waste Polystyrene in Virgin Bitumen. International Journal of Pavement Research and Technology. (0123456789):

4. Kalantar, Z.N., Karim, M.R., and Mahrez, A. 2012. A review of using waste and virgin polymer in pavement. Construction and Building Materials. 33 55-62.

5. Baytekin, B., Baytekin, H.T., and Grzybowski, B.A. 2013. Retrieving and converting energy from polymers: Deployable technologies and emerging concepts. Energy and Environmental Science. 6 (12): 3467-3482.

6. Hearon, K., Nash, L.D., Rodriguez, J.N., Lonnecker, A.T., Raymond, J.E., Wilson, T.S., Wooley, K.L., and Maitland, D.J. 2014. A high-performance recycling solution for polystyrene achieved by the synthesis of renewable poly(thioether) networks derived from d -limonene. Advanced Materials. 26 (10): 1552 1558 .

7. Pol, V.G. 2010. Upcycling: Converting waste plastics into paramagnetic, conducting, solid, pure carbon microspheres. Environmental Science and Technology. 44 (12): 4753-4759.

8. Mohamed, N., Maharaj, R., and Ramlochan, D. 2017. Rutting and fatigue cracking susceptibility of polystyrene modified asphalt. Am J Appl Sci. 14 (5): 583-591.

9. Casey, D., McNally, C., Gibney, A., and Gilchrist, M.D. 2008 Development of a recycled polymer modified binder for use in stone mastic asphalt. Resources, Conservation and Recycling. 52 (10): 1167-1174.

10. Polacco, G., Berlincioni, S., Biondi, D., Stastna, J., and Zanzotto, L. 2005. Asphalt modification with different polyethylene-based polymers. European Polymer Journal. 41 (12): 2831-2844.

11. Baker, M.B., Abendeh, R., Abu-Salem, Z., and Khedaywi, T. 2016. Production of sustainable asphalt mixes using recycled polystyrene. International Journal of Applied Environmental Sciences. 11 (1): 183-192.

12. Padhan, R.K., Sreeram, A., and Gupta, A. 2020. Evaluation of trans-polyoctenamer and cross-linking agents on the performance of waste polystyrene modified asphalt. Road Materials and Pavement Design. 21 (4): 1170-1182.

13. Barzegari, M.R., Yousefi, A.A., and Zeynali, M.E. 2002. Bitumen modification via PS/PB Blend. Iranian Journal of Polymer Science and Technology (Persian).

14. Vila-Cortavitarte, M., Lastra-González, P., Calzada-Pérez, M.Á., and Indacoechea-Vega, I. 2018. Analysis of the influence of using recycled polystyrene as a substitute for bitumen in the behaviour of asphalt concrete mixtures. Journal of Cleaner Production. 170 1279-1287.

15. Samper, M.D., Garcia-Sanoguera, D., Parres, F., and López, J. 2010. Recycling of expanded polystyrene from packaging. Progress in Rubber, Plastics and Recycling Technology. 26 (2): 83-92.

16. Nciri, N., Shin, T., and Cho, N. 2020. Towards the Use of Waste 
Expanded Polystyrene as Potential Modifier for Flexible Road Pavements. Materials Today: Proceedings. 24 763-771.

17. SohrabVeiseh and Yousefi, A.A. 2021. Compressive behavior and thermal conductivity-density correlation of expanded polystyrene thermal insulators. Iranian Polymer Journal. (0123456789):

18. Ramli Sulong, N.H., Mustapa, S.A.S., and Abdul Rashid, M.K. 2019. Application of expanded polystyrene (EPS) in buildings and constructions: A review. Journal of Applied Polymer Science. 136 (20): 1-11.

19. Nassar, I.M., Kabel, K.I., and Ibrahim, I.M. 2012. Evaluation of the Effect of Waste Polystyrene on Performance of Asphalt Binder. ARPN Journal of Science and Technology. 2 (10): $927-$ 935.

20. Al-Haydari, I.S.J. and Masued, G.G. 2017. Benefit of Using Expanded Polystyrene Packaging Material To Improve Pavement Mixture Properties. Applied Research Journal. 3 (11): 332-342.

21. Murana, A.A., Akilu, K., and Olowosulu, A.T. 2021. Use of expanded polystyrene from disposable food pack as a modifier for bitumen in hot mix asphalt. Nigerian Journal of Technology. 39 (4): 1021-1028.

22. TÜPRAŞ 2020. Product Specification.

23. Pfeiffer, J.P. and Van Doormaal, P.M. 1936. The rheological properties of asphaltic bitumens. Journal of the Institute of Petroleum Technologists. 22 414-440.

24. Fisher, R.A. 1992. Statistical methods for research workers. in: Breakthroughs in Statistics, Springer: pp. 66-70.

25. Bennert, T., Reinke, G., Mogawer, W., and Mooney, K. 2010. Assessment of workability and compactability of warm-mix asphalt. Transportation Research Record. (2180): 36-47.

26. Fontes, L.P.T.L., Trichês, G., Pais, J.C., and Pereira, P.A.A. 2010. Evaluating permanent deformation in asphalt rubber mixtures. Construction and Building Materials. 24 (7): 1193-1200.

27. Tabatabaee, H., Clopotel, C., Arshadi, A., and Bahia, H. 2013. Critical problems with using the Asphalt ductility test as a performance index for modified binders. Transportation Research Record. (2370): 84-91.

28. Ruan, Y., Davison, R.R., and Glover, C.J. 2003. An investigation of asphalt durability: Relationships between ductility and rheological properties for unmodified asphalts. Petroleum Science and Technology. 21 (1-2): 231-254.

29. Arslan, D., Gürü, M., and Çubuk, M.K. 2013. Bitüm ve Bitümlü Karışımların Performans Özelliklerinin Organik Esaslı Çinkofosfat Bileşiği İle Geliştirilmesi. Gazi Üniversitesi Mühendislik Mimarlık Fakültesi Dergisi. 27 (2):.

30. Elkholy, S.A., Abd El-Rahman, A.M.M., El-Shafie, M., and AboShanab, Z.L. 2018. Physical and rheological properties of modified sulfur asphalt binder. International Journal of Pavement Research and Technology. 11 838-845.

31. Firoozifar, S.H., Foroutan, S., and Foroutan, S. 2011. The effect of asphaltene on thermal properties of bitumen. Chemical Engineering Research and Design. 89 (10): 2044-2048.

32. Alsheyab, M.A.T. and Khedaywi, T.S. 2013. Effect of electric arc furnace dust (EAFD) on properties of asphalt cement mixture. Resources, Conservation and Recycling. 70 38-43.

33. Read, J. and Whiteoak, D. The Shell Bitumen Handbook Fifth edition, Exhibit 1008; Thomas Telford Publishing: 2003. 